\title{
Thermal Power Plant Condenser Fault Diagnosis Using Coordinated Condition Monitoring Approach
}

\author{
Hanumant Pandurang Jagtap ${ }^{1}$, Anand Bewoor ${ }^{2}$, Ravinder Kumar ${ }^{3 *}$ \\ ${ }^{1}$ Zeal College of Engineering and Research, Narhe, Pune, India \\ ${ }^{2}$ Mechanical Engineering Department, Cummins College of Engineering for Women, Pune, India \\ ${ }^{3}$ School of Mechanical Engineering, Lovely Professional University, Phagwara, Punjab, India
}

Corresponding Author Email: rav.chauhan@yahoo.co.in

https://doi.org/10.18280/i2m.180301

Received: 19 March 2019

Accepted: 20 May 2019

\section{Keywords:}

reliability analysis, preventive maintenance, vibration analysis, noise measurement, ultrasound

\begin{abstract}
The purpose of this study is the fault diagnosis of the cooling water pump of the condenser system used in thermal power plant using coordinated condition monitoring approach. The approach is based on integrating condition monitoring techniques, viz., vibration analysis, noise analysis, and ultrasound analysis. The failure data and repair data of condenser system are collected and analyzed for reliability analysis. The reliability-based preventive maintenance time intervals are determined at different levels, such as at $90 \%, 75 \%$, and $50 \%$. In addition, K-S goodness of fit test is carried out, and the best-fit distribution reliability parameters have been obtained. Such determined reliability-based time interval is counted to plan, not only maintaining/repairing work but also for replacement of the component/equipment. A case study showing reliability improvement of the condenser is reported in the present study. Through this study, the fault of the cooling water pump of the condenser system is diagnosed using coordinated condition monitoring approach. It was found that the bearing of the cooling water pump was damaged. The pump bearing was replaced during the maintenance work. The performance of the cooling water pump was analyzed and found in a normal state. It is concluded that coordinated condition monitoring approach improves the accuracy of fault detection and diagnosis.
\end{abstract}

\section{INTRODUCTION}

The increasing need for electricity has brought about the importance of maintaining power generating resources on a higher priority in India. Among the various resources, the thermal power plant is the primary resource of electricity generation. It is essential to maintain the thermal power plant continuously in an operating state. Unfortunately, this is not the case because the failure of equipment is inevitable even though it can be minimized by implementing suitable maintenance strategy. Garg [1] presented a methodology for analyzing the performance of industrial systems using uncertain data. The reliability, availability, and maintenance of thermal power plant have become more significant in recent years due to the growing demand for electricity from society. The optimum reliability and availability level are desirable not only to reduce the overall cost of production but also to reduce the risk of hazards [2]. The basic reliability and operational reliability are forecasted on the basis of the forecasted value of per unit contained in the model [3]. However, with thoughtful consideration for reliability, availability, and maintainability, the frequency of failures and similar consequences can be reduced considerably. Eti et al. [4] claimed that, if the attention is given during maintenance planning regarding the maintenance needs of the system, considerable savings are achieved in operational processes.

As, the thermal power plant is a complex system consisting of various subsystems connected either in series, parallel, or mixed configuration. Failure of any subsystem may cause its unavailability, which will affect the performance of the system/unit/plant. Kumar et al. [5] developed the availability simulation model for power generation system of the thermal power plant and investigated the performance of the system under realistic working conditions. Dev et al. [6] stated that criticality level decides the importance of the system as well as a choice of appropriate maintenance and repair strategy so that the reliability and availability may be maintained up to the mark. According to Carazas et al. [7], reliability can be at least estimated during the plant design stages because its availability is strongly influenced by major factors such as the ability to diagnose the cause of the failure or the availability of equipment and skilled personnel to carry out the repair procedure.

The several approaches/tools have been used by earlier researchers to evaluate the reliability and availability parameters. Garg et al. [8] solved reliability redundancy allocation problem for non-linear source constraints. In their study, the artificial bee colony is developed, and further, the solutions are obtained with improvements. In addition, Garg [9] extended their study for obtaining the optimal solution of reliability redundancy allocation problem by using penalty based cuckoo search with non-linear constraints. Kumar et al. [10] classified the major systems of the thermal power plant into five different categories viz. boiler (boiler furnace and steam drum), boiler air circulation system, water circulation system, coal supply system and power generating system (steam turbine and a generator unit). In case of such condenser subsystem, condensate leaving the condenser is supply to the 
low-pressure heater, boiler feed pump through condensate extraction pump, which increases the pressure. Then, the temperature of the water is increased by passing it through a high-pressure heater and economizer. The boiler produces steam and stored in boiler drum which will further supplies to a steam turbine for electricity generation. Therefore, condenser subsystem is one of the essential prime systems of the thermal power plant. The reliability of condenser subsystem needs to maintain a high level.

In order to analyze the performance of the condenser subsystem for attaining the high availability and reliability, the reliability characteristics need to be studied in detail. This study reported a reliability analysis of the condenser system of Dahanu Thermal Power Plant (DTPP). In order to study the behavior of the system, the reliability of the condenser system at different time interval is determined. In addition, this study proposes a coordinated condition monitoring approach for fault detection of critical equipment of the plant. The approach is based on integrating three condition monitoring techniques, which includes vibration analysis, noise measurement, and ultrasound level. Through this study, the fault of the pump driving end bearing of the auxiliary cooling water pump (CWP) is diagnosed. The details of the work done are discussed in subsequent sections.

The structure of the paper is organized as; Section 2 introduces reliability analysis for the condenser system, Section 3 provides details of coordinated condition monitoring approach based case study. The results and discussion are described in Section 4. Further, Section 5 highlighted the findings of the study.

\section{RELIABILITY ANALYSIS FOR CONDENSER SYSTEM OF THE THERMAL POWER PLANT}

The effectiveness of thermal power plant is mainly influenced by the availability, reliability, and maintainability of the plant. Reliability, maintainability, and availability analysis are very much effective methods for finding critical subsystems of the plant. These methods provide a base for implementing suitable maintenance program. In this study, an attempt is made for estimating reliability-based preventive maintenance intervals for the condenser system of the thermal power plant. The reliability of the system is evaluated at various levels, such as at $90 \%, 75 \%$, and $50 \%$. The failure data and repair data of condenser system are collected and analyzed for reliability analysis. The K-S Goodness test is carried out for determination of best-fit distribution curve for time to failure data and time to repair data of selected equipment. The reliability parameters are determined for the best-fit distribution curve, and then reliability analysis is carried out.

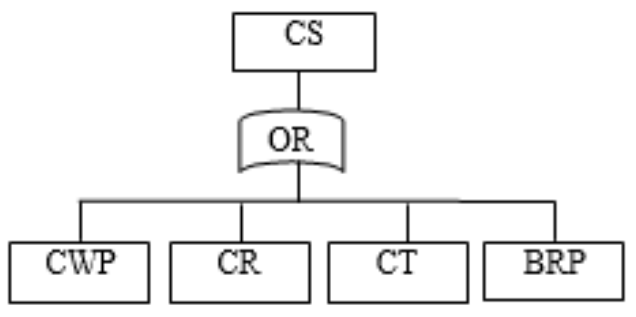

Figure 1. Fault tree diagram of the condenser system

The condenser system consists of a cooling water pump, condenser tube, and ball recirculation pump. The components of the condenser system are connected in a series configuration, and the fault tree diagram is as shown in Figure 1.

The failure dataset and repair dataset of condenser system is collected and examined using Kolmogorov-Smirnov (K-S) goodness of fit test. The advantage of the K-S test is that no restriction for sample size and hence adapted for this study. The best-fit parameters used for statistical distribution were computed using Reliasoft Weibull++ software [11]. The corresponding results are obtained for the condenser systems are tabulated in Table 1.

Table 1. Best-fit distribution of condenser system

\begin{tabular}{|c|c|c|c|c|c|c|c|c|}
\hline \multirow[b]{2}{*}{ Equipment } & \multicolumn{6}{|c|}{ K-S test (goodness of fit) } & \multirow{2}{*}{$\begin{array}{c}\text { Best-fit } \\
\text { distribution }\end{array}$} & \multirow[b]{2}{*}{ Parameters } \\
\hline & $\begin{array}{l}\text { Exp. } \\
1 P\end{array}$ & $\begin{array}{l}\text { Exp. } \\
2 P\end{array}$ & Log-normal & Normal & Weibull 2P & Weibull 3P & & \\
\hline CWP & 78.20 & 0.1331 & 0.2671 & 26.05 & 6.1607 & $0.579 \mathrm{e}-4$ & $\begin{array}{l}\text { Weibull } \\
\text { 3P }\end{array}$ & $\begin{array}{c}\beta=0.81 \theta=7544 \\
\gamma=3625\end{array}$ \\
\hline $\mathrm{CR}$ & 95.56 & 76.06 & 1.8067 & 1.3777 & 1.5740 & 12.06 & $\begin{array}{l}\text { Normal- } \\
2 \mathrm{P}\end{array}$ & $\begin{array}{l}\mu=19322.1 \\
\sigma=5859.22\end{array}$ \\
\hline $\mathrm{CT}$ & 95.56 & 76.06 & 1.8067 & 1.3777 & 1.5740 & 12.06 & $\begin{array}{l}\text { Normal- } \\
2 \mathrm{P}\end{array}$ & $\begin{array}{l}\mu=19322.1 \\
\sigma=5859.22\end{array}$ \\
\hline BCR & 95.56 & 76.06 & 1.8067 & 1.3777 & 1.5740 & 12.06 & $\begin{array}{l}\text { Normal- } \\
2 \mathrm{P}\end{array}$ & $\begin{array}{l}\mu=19322.1 \\
\sigma=5859.22\end{array}$ \\
\hline
\end{tabular}

It is observed from Table 1 that, most of the equipment of the condenser system follows a normal-2P distribution as best suited except CWP (Weibull-3P). The normal distribution shows a growing failure rate due to the aging of the component/equipment/system. It requires a consistently fixed interval of time to complete the maintenance task and repair actions. Hence, preventive maintenance is required for such component/equipment/system within a specified time interval. In the case of CWP, the shape parameter ' $\beta$ ' for Weibull distribution is less than 1. It indicates that it is due to decreasing failure, which occurs in early life or debugging period for which the breakdown maintenance is best suitable.
The probability density function for a normal distribution is given by Eq. (1), and the corresponding reliability is calculated by Eq. (2). Similarly, the reliability characteristics for Weibull distribution by neglecting the location parameter $(\gamma)$ are estimated by using Eq. (3).

$$
\begin{gathered}
F(t)=\frac{1}{\sigma \sqrt{2 \pi}} e^{-\left(\frac{t-\mu}{\sigma}\right)^{2}} \\
R(t)=1-F(t)
\end{gathered}
$$




$$
R(t)=e^{-\left(\frac{t}{\theta}\right)^{\beta}}
$$

Here, $\beta$ termed as shape parameter, $\theta$ termed as scale parameter, $\sigma$ termed as variance and $t$ is a time factor. The reliable life of selected equipment of the condenser system at a defined reliability level is tabulated in Table 2.

Table 2. Reliable life of condenser system

\begin{tabular}{cccccc}
\hline \multirow{2}{*}{ Equipment } & \multicolumn{5}{c}{ Reliable Life in Hrs } \\
\cline { 2 - 6 } & $\mathbf{9 0 \%}$ & $\mathbf{8 5} \%$ & $\mathbf{7 5 \%}$ & $\mathbf{6 5 \%}$ & $\mathbf{5 0 \%}$ \\
\hline CWP & 4102 & 4437 & 5262 & 6311 & 8438 \\
Condenser & 11813 & 13249 & 15370 & 17064 & 19322 \\
Condenser tube & 11813 & 13249 & 15370 & 17064 & 19322 \\
Ball recir. pump & 11813 & 13249 & 15370 & 17064 & 19322 \\
\hline
\end{tabular}

It is observed from Table 2 that, for CWP, the maintenance task should be completed before $4102 \mathrm{Hrs}$ for attaining the reliability level of $90 \%(\mathrm{R}=0.9)$. The CWP for CWP is identified as the most critical equipment of the condenser system. Therefore, essential steps need to be taken to improve the reliability of such critical equipment of DTPP, which in turn enhance the system availability. In the case of other systems of the condenser system, it should complete before $11813 \mathrm{Hrs}$. Intending to run equipment at $90 \%$ reliability level, it leads to high cost. So, the reliability of $75 \%$ level is advised for the beginning stages of operation and later on, the advantage of safety, effectiveness, and cost are accustomed to the superior level of reliability. Such determined reliabilitybased time interval is counted to plan not only maintaining/repairing work but also for replacement of the component/equipment. The study adds value to the benefit of safety implication and cost factors. Such valid suggestions are advised for scheduling preventative maintenance of the condenser system.

In this study, the components of the condenser system are in a series configuration, and the reliability is evaluated for the series configuration of equipment using Eq. (4).

$$
R_{s}(t)=\prod_{i=1}^{n} R_{i}(t)
$$

The reliability of at various time intervals of the condenser system is evaluated and which is tabulated in Table 3.

Table 3. Overall reliability of condenser system at various time intervals

\begin{tabular}{cccccc}
\hline Time & CWP & CR & CT & BRP & $\begin{array}{c}\text { System } \\
\text { Reliability }\end{array}$ \\
\hline 0 & 1 & 1 & 1 & 1 & 1.00 \\
720 & 1 & 0.9992 & 0.9992 & 0.9992 & 1.00 \\
2160 & 1 & 0.9983 & 0.9983 & 0.9983 & 0.99 \\
4320 & 0.8667 & 0.9947 & 0.9947 & 0.9947 & 0.85 \\
6480 & 0.635 & 0.9858 & 0.9858 & 0.9858 & 0.61 \\
8760 & 0.4815 & 0.9642 & 0.9642 & 0.9642 & 0.43 \\
10800 & 0.3829 & 0.927 & 0.927 & 0.927 & 0.31 \\
12960 & 0.3043 & 0.8612 & 0.8612 & 0.8612 & 0.19 \\
15120 & 0.2442 & 0.7633 & 0.7633 & 0.7633 & 0.11 \\
17520 & 0.1929 & 0.6207 & 0.6207 & 0.6207 & 0.05 \\
\hline
\end{tabular}

It is observed from Table 3 that, overall system reliability of condenser system reduces rapidly after the operational time of 2160 Hrs. Moreover, reliability reduces to $61 \%$ for the operating time of $6480 \mathrm{Hrs}$. Hence, it is essential to note that CWP, CR, CT, and BRP affect the overall reliability of the condenser system. The necessary measures must be taken for such critical systems of a condenser system for improvement in reliability and availability of DTPP. The next section discussed the reliability improvement of CWP by using coordinated condition monitoring approach as a case study.

\section{RELIABILITY IMPROVEMENT OF CONDENSER SYSTEM USING COORDINATED CONDITION MONITORING APPROACH: A CASE STUDY}

The reliability and availability of the thermal power plant can be maintained high by adopting condition monitoring techniques for diagnosing the fault before the system breakdown. Bhargava et al. [12] predicted the reliability of thyristor using artificial intelligence techniques. The fault detection, fault diagnosis, and making maintenance-related decisions are made in the process of the condition monitoring program [13]. In recent years, various effective condition monitoring techniques have been developed, which includes vibration analysis, acoustic emission monitoring, wear debris analysis, thermography, temperature analysis, ultrasonic monitoring, non-destructive testing, visual inspection, motor condition monitoring, and motor current signature analysis. Use of such condition monitoring based maintenance strategy has not only been widely recommended by earlier researchers but also adopted by industries at large.

The studies reported by earlier researchers have intended to use integrated condition monitoring techniques for fault diagnosis [14]. Jagtap et al. [15] proposed an algorithm for fault identification of fault occurred in thermal power plant equipment using coordinated condition monitoring approach. The major reason to use such a program is to increase the accuracy of fault detection. Figure 2 shows the coordinated condition monitoring approach which contains vibration analysis technique, noise measurement, and ultrasound measurement.

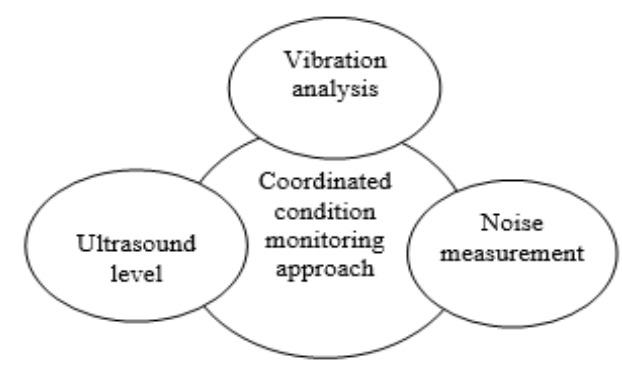

Figure 2. Coordinated condition monitoring approach

According to the approach, the current health of the selected system can be known by collecting and analyzing the condition monitoring data in the form of vibration parameter level, a noise parameter, and high-frequency ultrasound level. If the monitored parameter exceeds the defined reference level, then the more attention is given on a high priority basis of such a critical system. By integrating all relevant information of process parameters of the selected system, the fault of the system is detected and diagnosed. The maintenance-related decisions are made, such as either to repair the failed component or to replace the component. In this study, the coordinated condition monitoring approach is adopted for diagnosing the fault of the auxiliary cooling water pump of the 
condenser system. The detailed study is discussed in the next section.

\subsection{Experimental set up}

The data acquisition system was used for collecting the condition monitoring data, which is presented in Figure 3. The accelerometer was placed on diving end (DE) and non-driving end (NDE) of motor bearing for ACWP 1B. The Fast Fourier transform analyzer recorded the vibration data (i.e., velocity and acceleration parameter) of ACWP 1B. The vibration measurements were taken along three directions, i.e., along the horizontal direction, vertical and axial direction.

The acceleration trend of ACWP 1B was analyzed to check the deviation in the vibration parameter, which is as shown in Figure 4.

It was observed that the acceleration trend of pump NDE in the horizontal direction was increased from $0.4 \mathrm{~g}$ level to 1.6 $\mathrm{g}$ level. The root causes which are affecting the acceleration parameters need to be carried out to avoid any future malfunction of ACWP 1B. At the same time, the overall vibration level (velocity parameter) of ACWP 1B were compared with reference standards and checked for threshold level. Figure 5 (a) to (h) shows the vibration spectrum before the maintenance obtained for velocity and acceleration parameter along the horizontal, vertical, and axial direction.

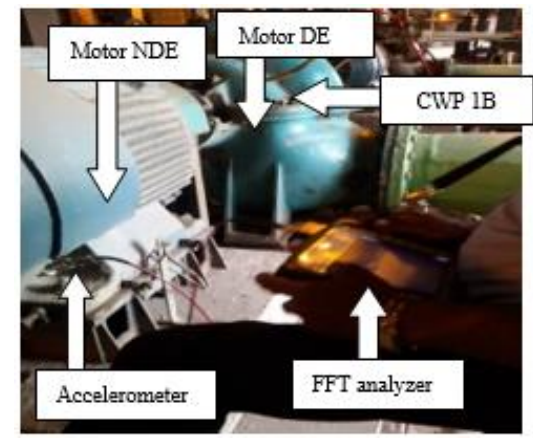

Figure 3. Data acquisition system used for ACWP 1B

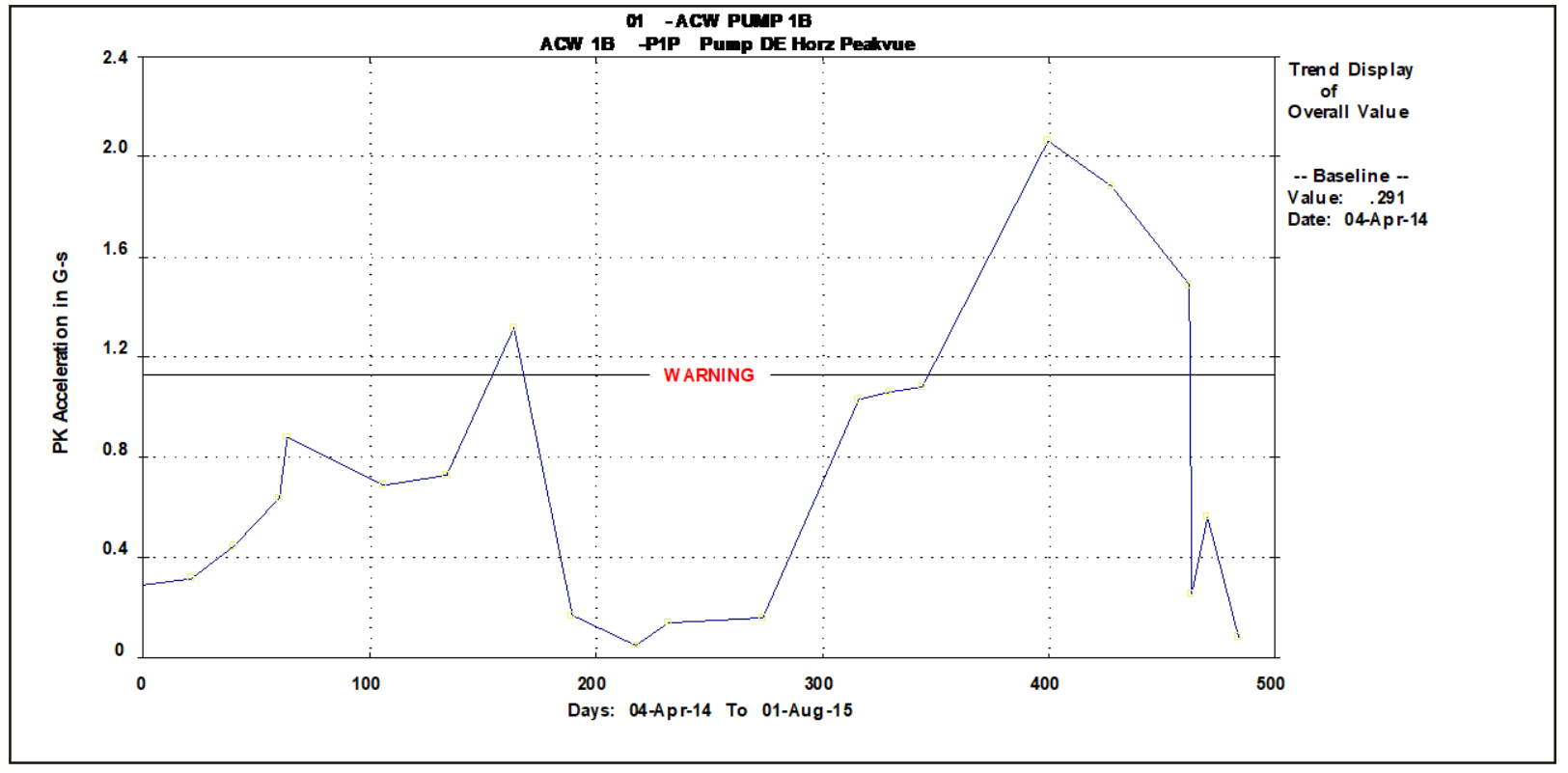

Figure 4. The trend of ACWP 1B (acceleration)

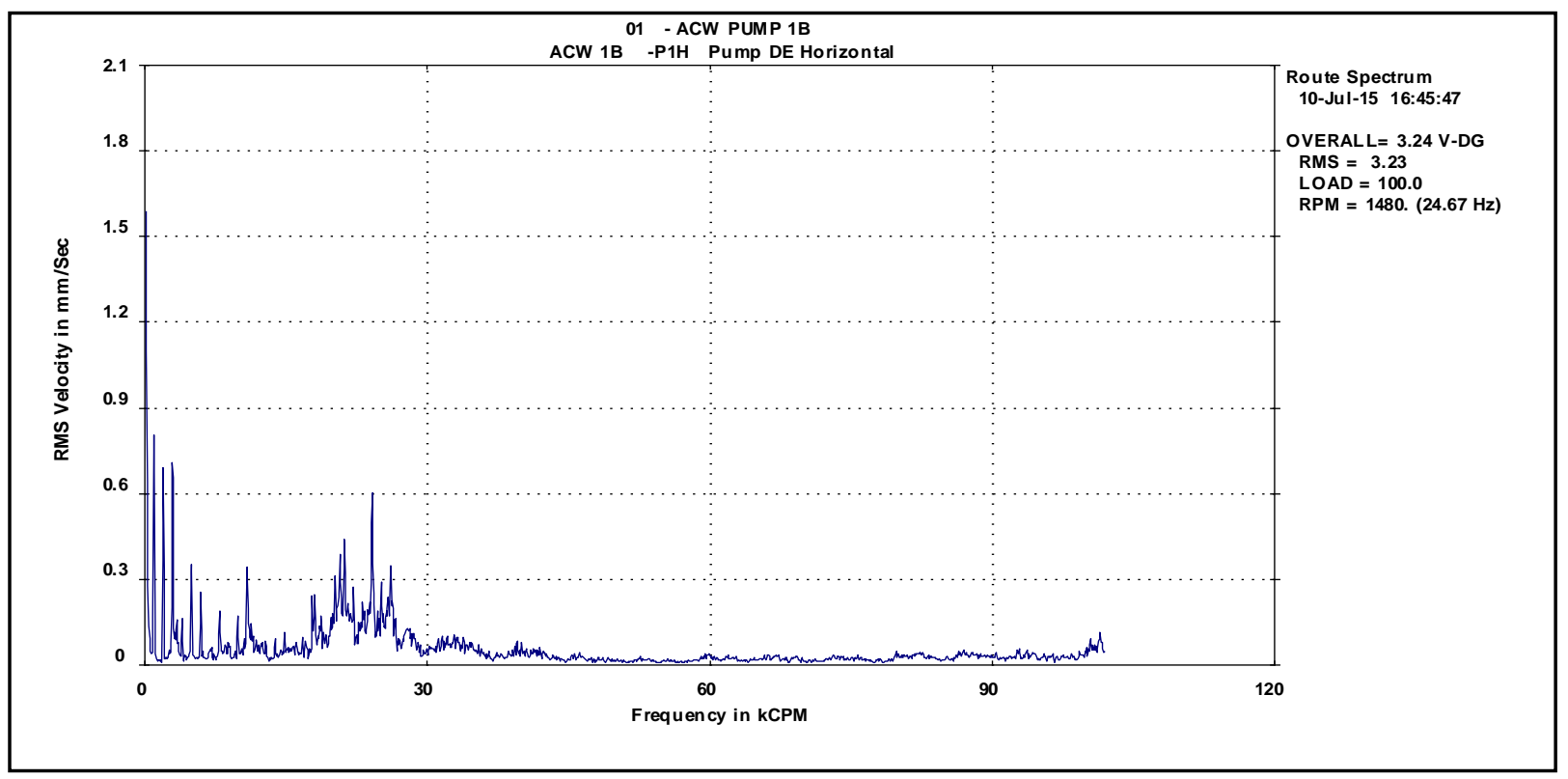

(a) Vibration spectrum (velocity) pump DE (horizontal) 


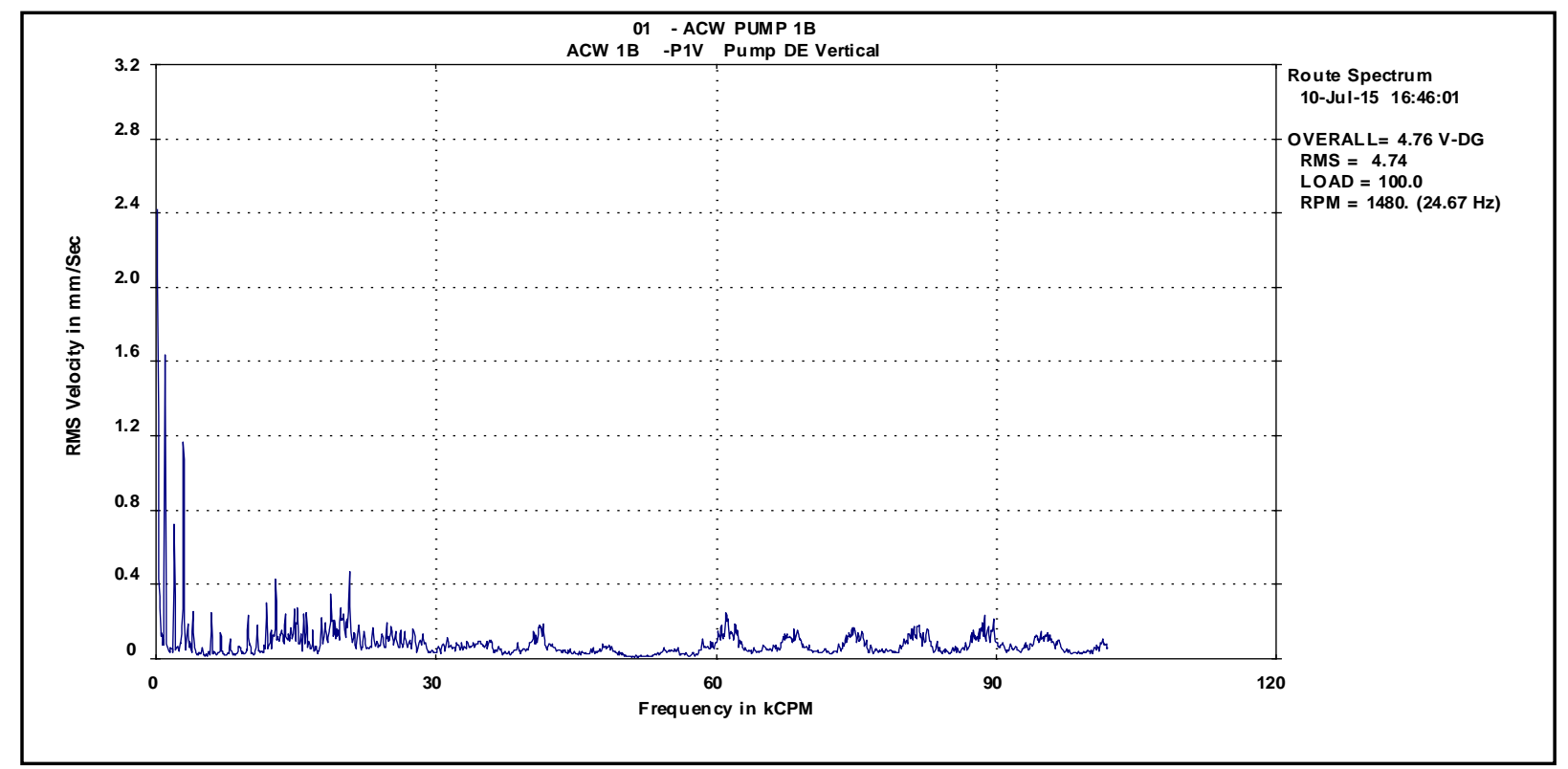

(b) Vibration spectrum (velocity) pump DE (vertical)

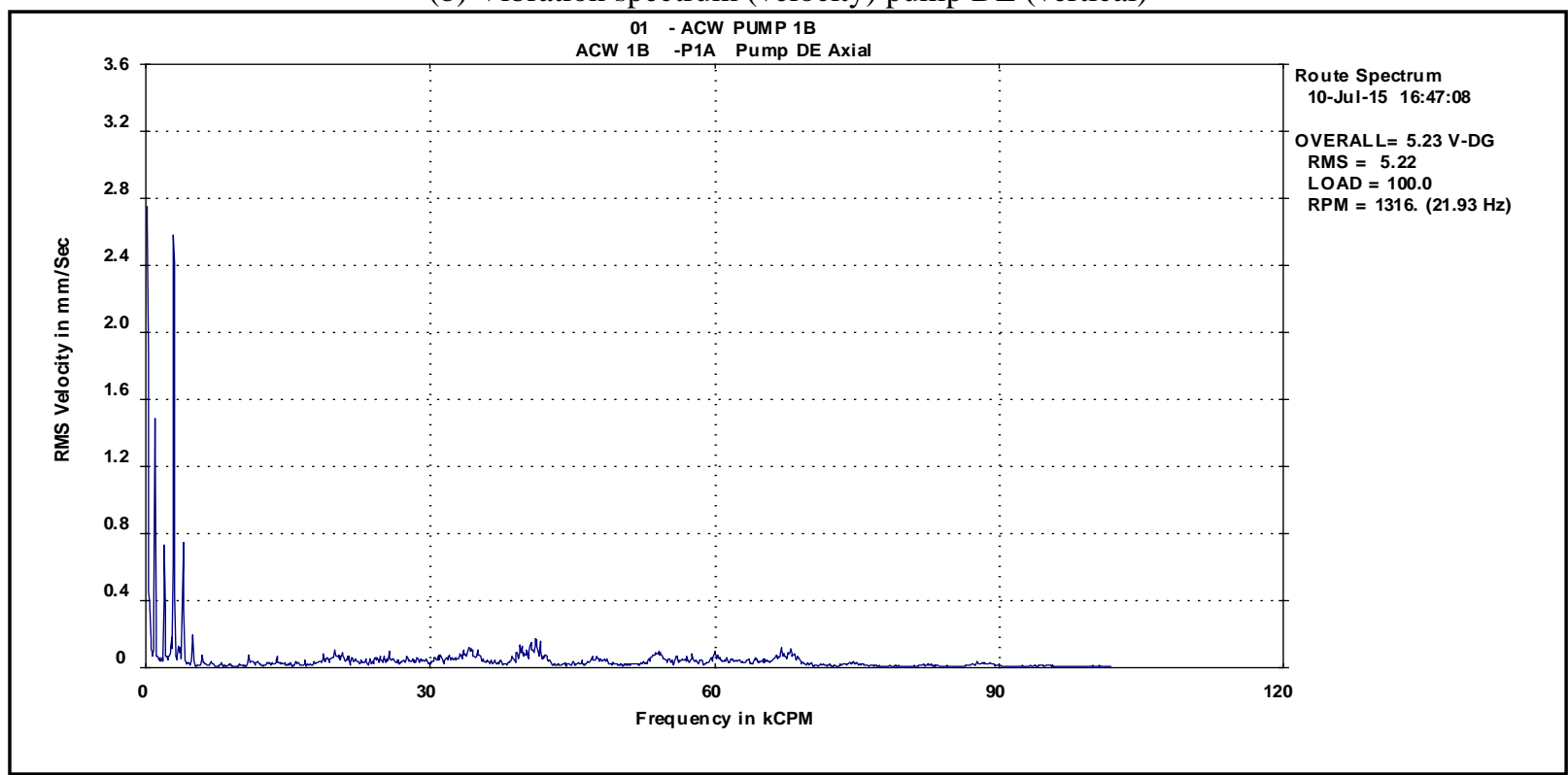

(c) Vibration spectrum (velocity) pump DE (axial)

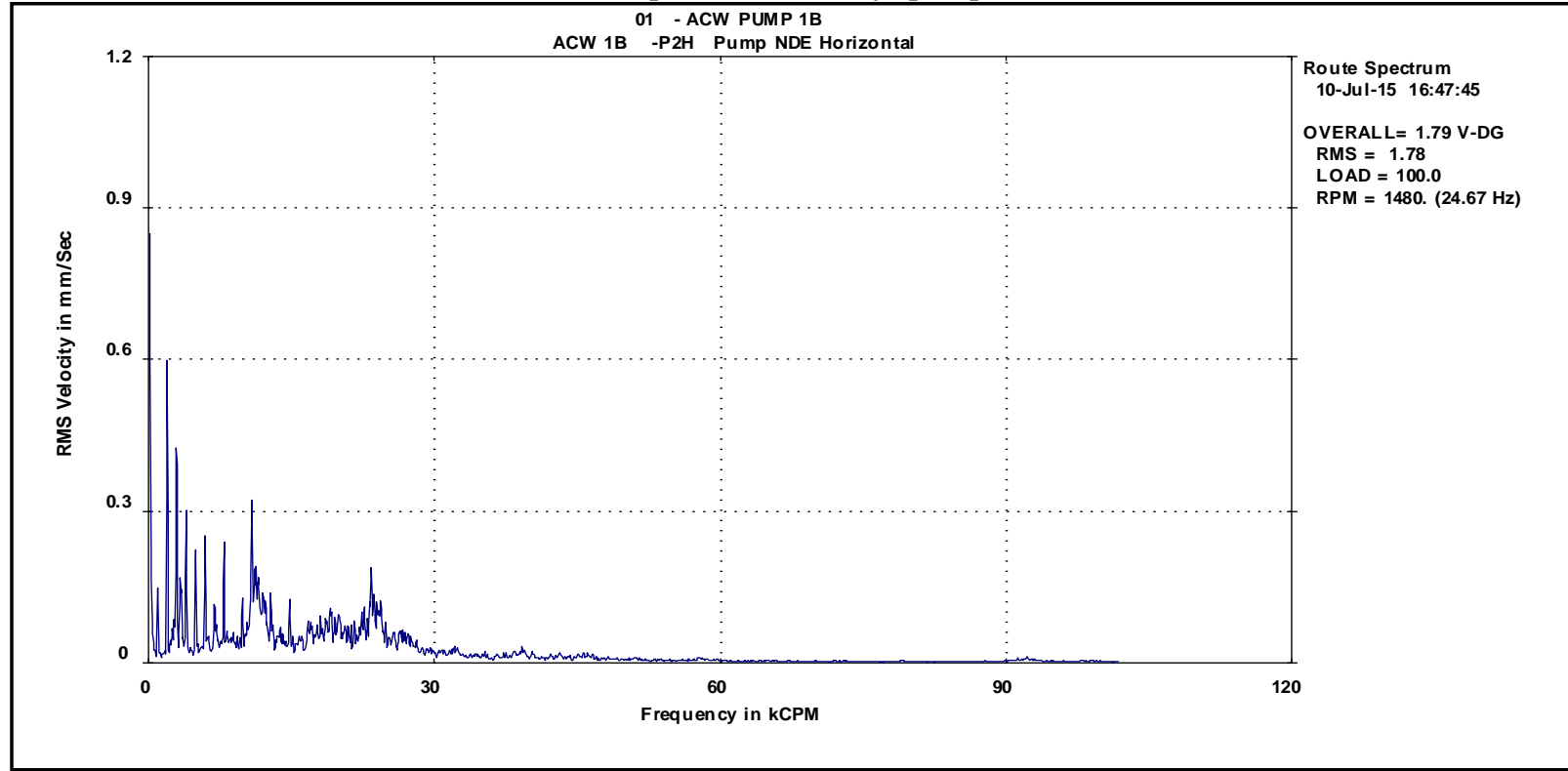

(d) Vibration spectrum (velocity) pump NDE (horizontal) 


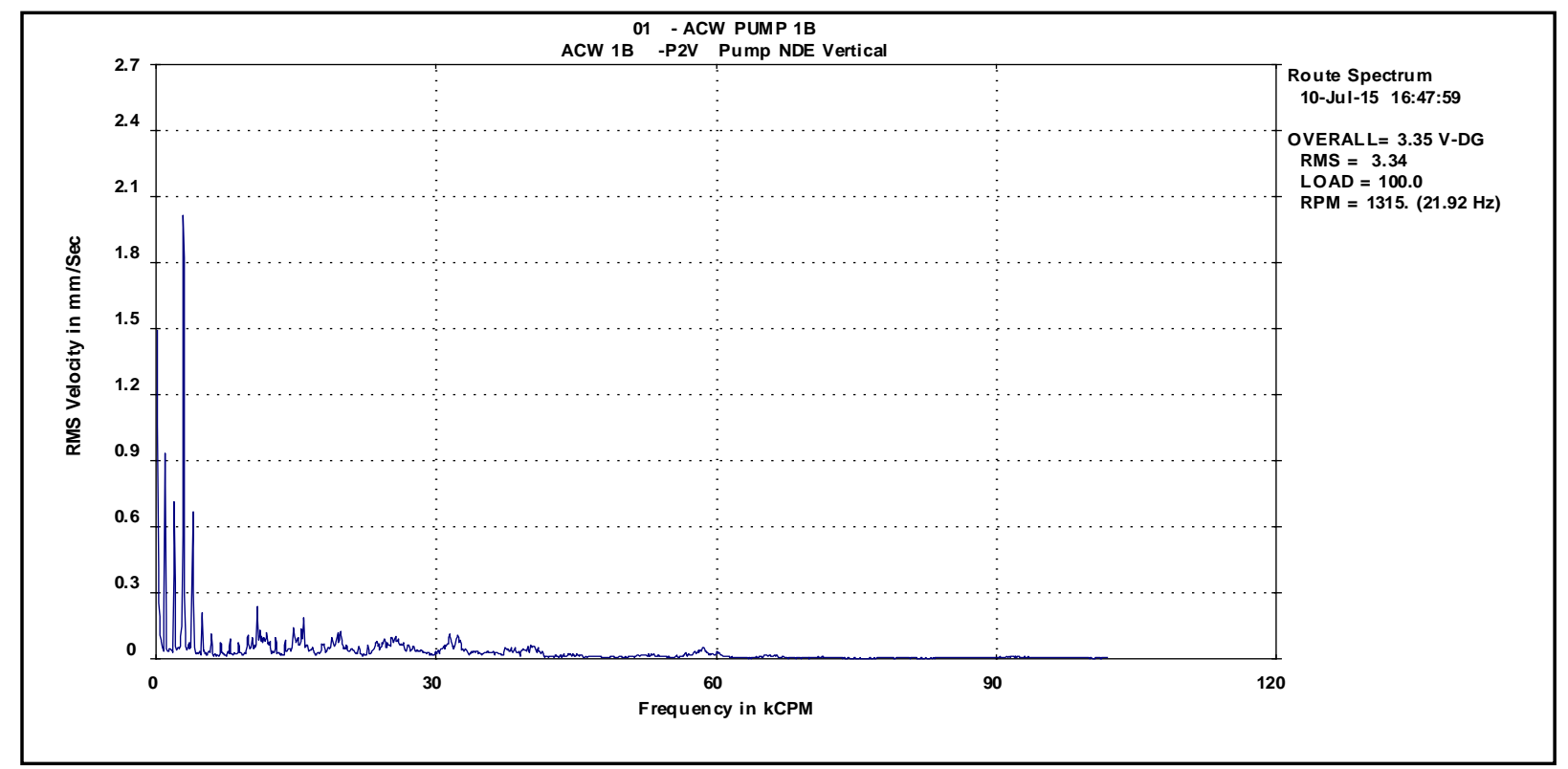

(e) Vibration spectrum (velocity) pump NDE (vertical)

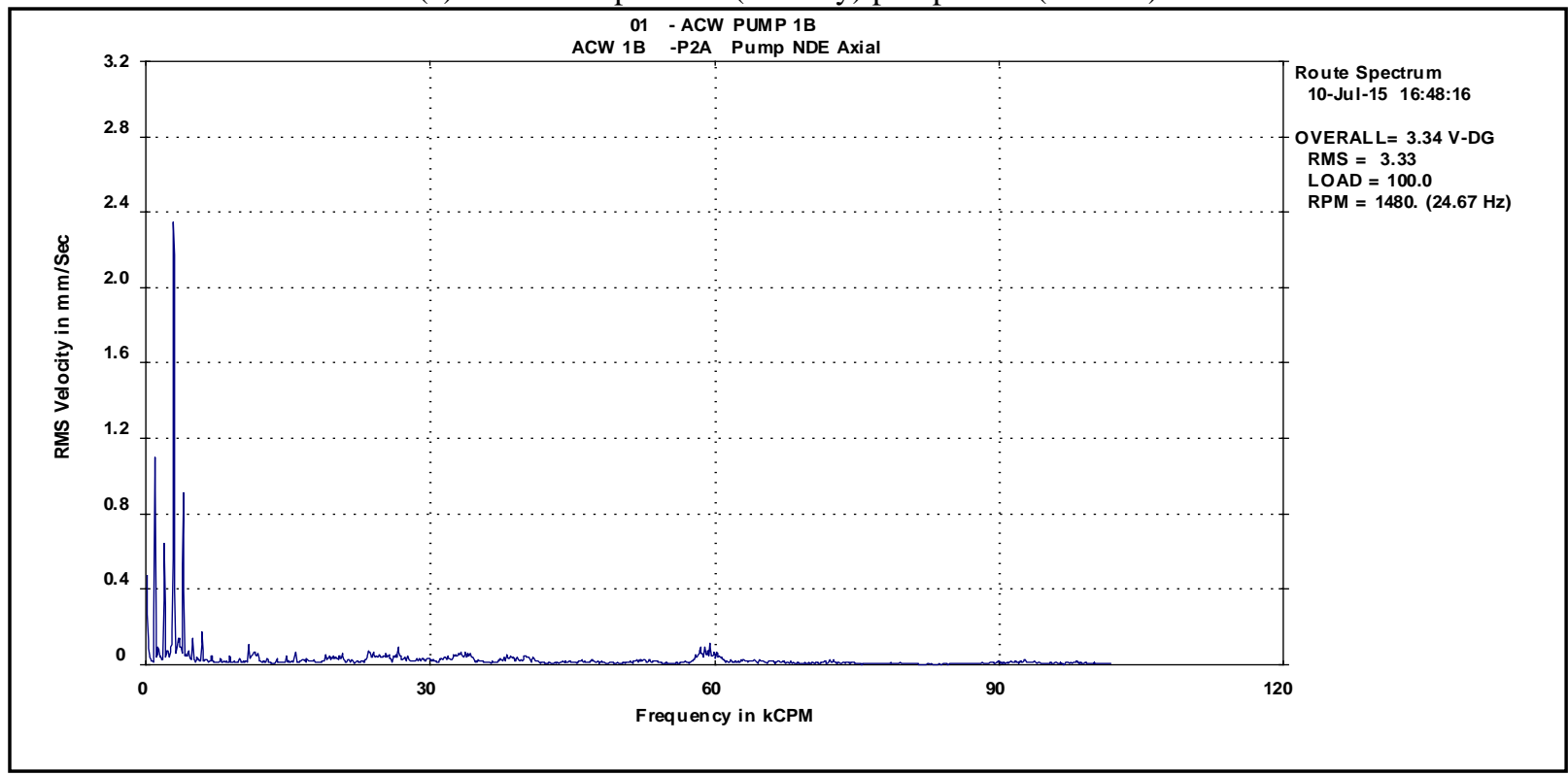

(f) Vibration spectrum (velocity) pump NDE (axial)

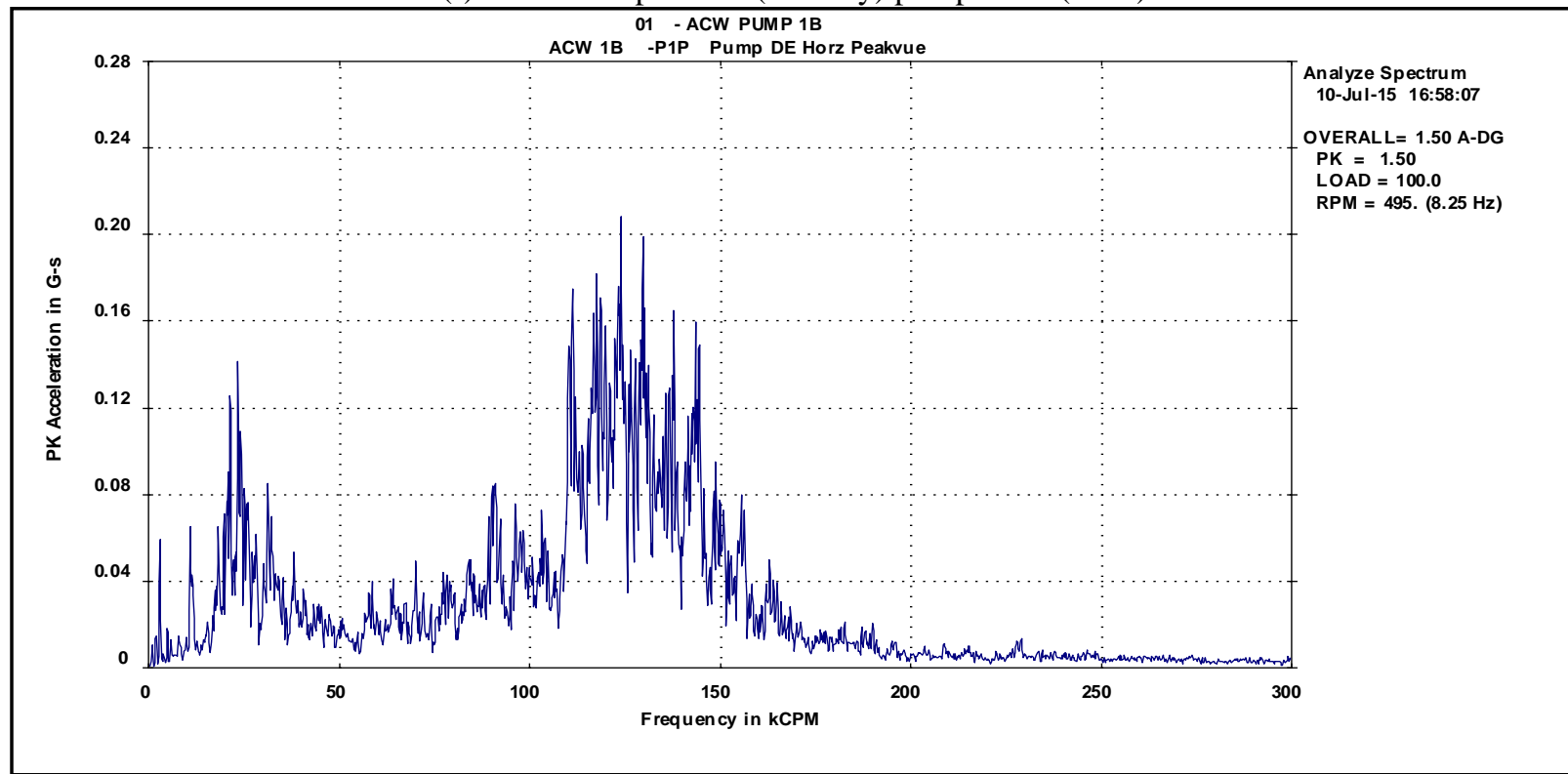

(g)Vibration spectrum (acceleration) pump DE (horizontal) 


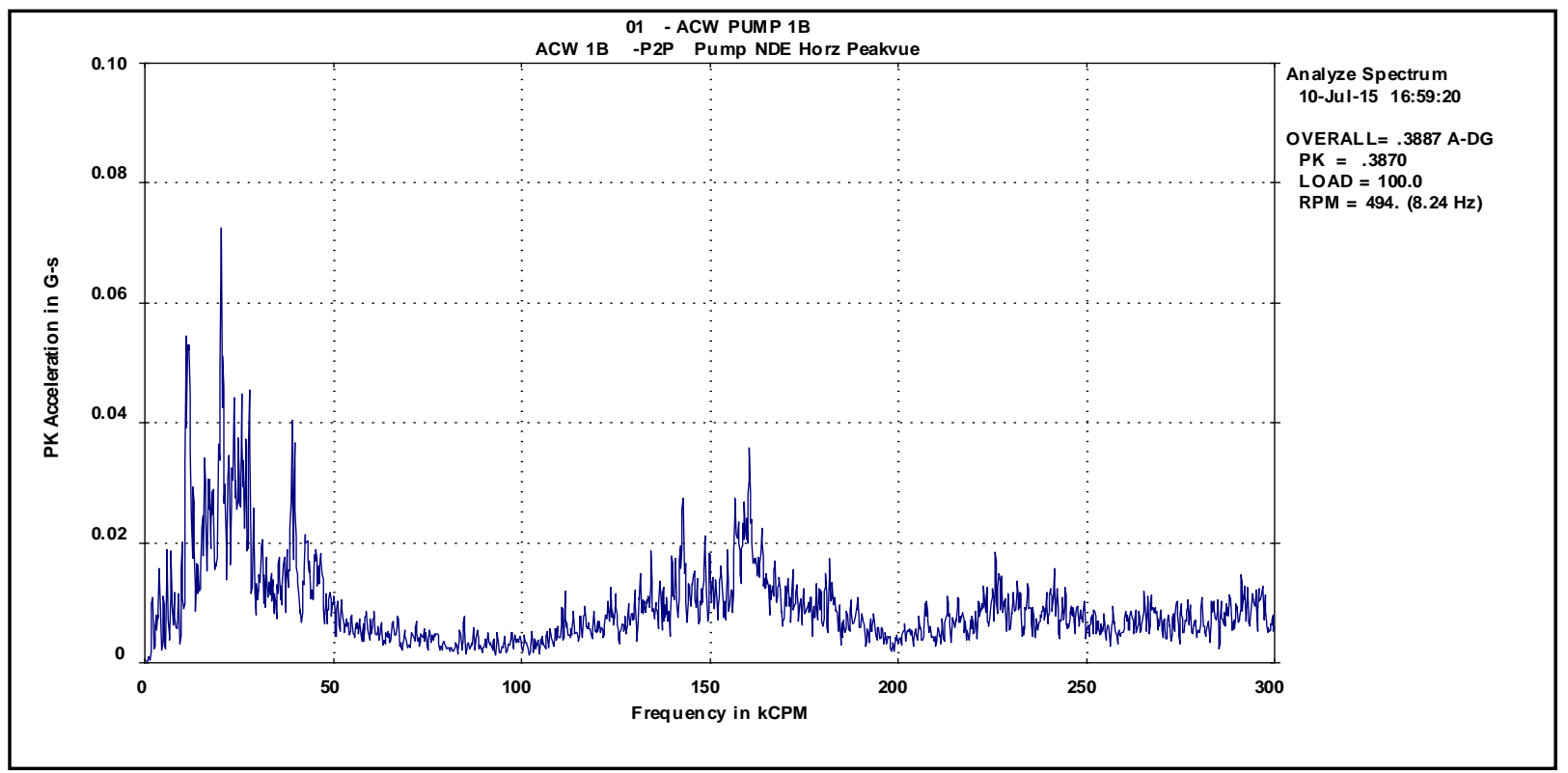

(h) Vibration spectrum (acceleration) pump NDE (horizontal)

Figure 5. Vibration spectrum before the maintenance

It was observed from Figure 5 that the velocity and acceleration parameters for pump DE bearings were increased to a significant level and recorded as $5.23 \mathrm{~mm} / \mathrm{sec}$ and $1.5 \mathrm{~g}$ respectively, which is tabulated in Table 4.

Table 4. Vibration parameters of ACWP 1B

\begin{tabular}{cccc}
\hline $\begin{array}{c}\text { Vibration } \\
\text { Parameter }\end{array}$ & $\begin{array}{c}\text { PUMP } \\
\text { DE }\end{array}$ & $\begin{array}{c}\text { PUMP } \\
\text { NDE }\end{array}$ & Remark \\
\hline H $(\mathrm{mm} / \mathrm{sec})$ & 3.24 & 1.79 & $\begin{array}{c}\text { Within } \\
\text { limit }\end{array}$ \\
V $(\mathrm{mm} / \mathrm{sec})$ & 4.76 & 3.35 & $\begin{array}{c}\text { Within } \\
\text { limit }\end{array}$ \\
A $(\mathrm{mm} / \mathrm{sec})$ & 5.23 & 3.34 & Warning \\
Acceleration $(\mathrm{g})$ & 1.5 & 0.38 & Warning \\
\hline
\end{tabular}

It is noted that the threshold level of vibration parameters of ACWP 1B was closer to the standard reference level (i.e.7 $\mathrm{mm} / \mathrm{sec}$ ). Therefore the fault of the system needs to identify and diagnosed correctly. The next section discussed the fault diagnosis using coordinated condition monitoring approach.

\subsection{Fault diagnosis using coordinated condition monitoring approach}

The coordinated condition monitoring approach assisted in identifying the fault of the system. The approach identifies the fault of the system accurately. Moreover, it provides a base for equipment maintenance decision. Three condition monitoring parameters are monitored using three techniques, which includes vibration monitoring, noise monitoring, and ultrasonic sound measurement. The acceleration spectrum of pump DE bearing was obtained using vibration analysis technique, which is as shown in Figure 6. Increased vibration parameters revealed that the fault of bearing has occurred. Therefore it is necessary to take corrective action before the system stop working.

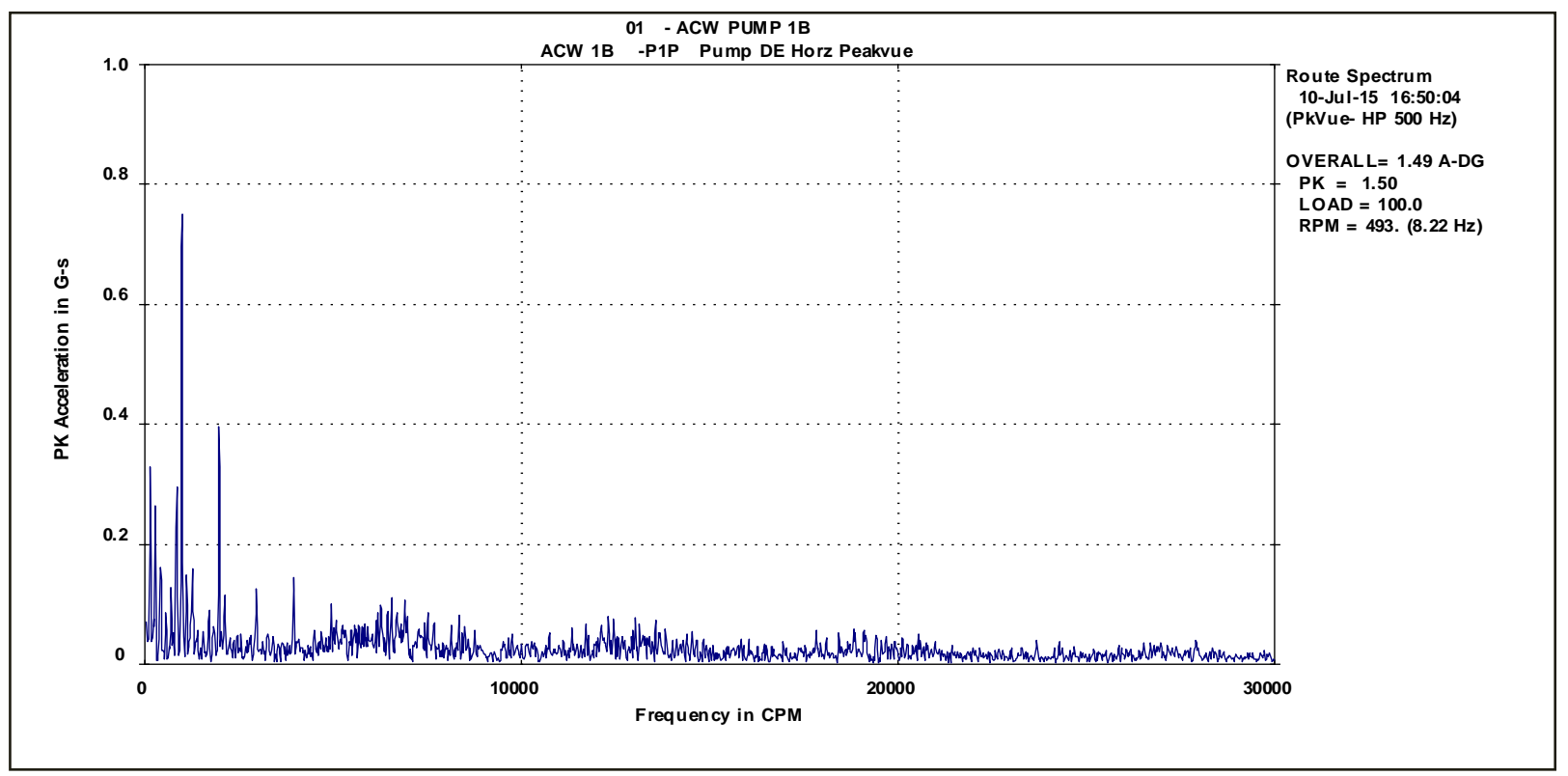

Figure 6. Acceleration spectrum of Pump DE bearing 
The major reasons behind the increasing trend of bearings are that most common rolling element bearing faults include damage of the inner race, the outer race, and the rolling elements. Generally, during the early stages of the fault, the surface is only locally affected, and vibrations are generated as a result of the repetitive impacts of the moving components on the defect.

It was observed from Figure 6 that "g" value was high on pump bearings and which causes to excite the high frequencies. These high frequencies are generated due to the presence of bearing defect frequencies. Thus it was suspected that pump bearings had been damaged. To confirm the bearing fault has occurred, the noise measurement and ultrasonic sound measurement were taken. At the same time, the sound level meter recorded as $95 \mathrm{~dB}$ of sound level closer to pump DE bearing, which is as shown in Figure 7. Simultaneously the ultrasonic meter showed the ultrasound level of $15 \mathrm{~dB}$ by blowing 5 led lights on the display panel of ultrasound meter. The final stage of fault diagnosis employed for comparing the observation recorded using three condition monitoring techniques. The vibration spectrum identified that measured "g" value was high on pump bearings and due to which the high frequencies got excited. These high frequencies happened due to the occurrence of bearing defect frequencies. Also, the noise level measured was $95 \mathrm{~dB}$, which was more than $90 \mathrm{~dB}$ reference level and ultrasound of $15 \mathrm{~dB}$ (blow of 5 Led lights on the display panel) was observed using the ultrasonic meter. Therefore it confirmed that the pump motor DE bearing had been damaged, which needs to be replaced as early. The decision was taken to disassemble the pump motor and replace the bearing.

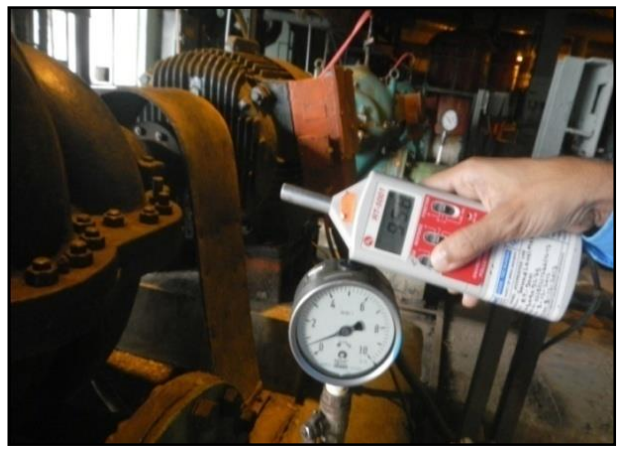

Figure 7. Sound level measurement

During the maintenance work, it was found that both motor bearing in a damaged condition, which is as shown in Figure 8. Furthermore, no Damage was observed on pump internals and pump impeller, which is as shown in Figure 9.

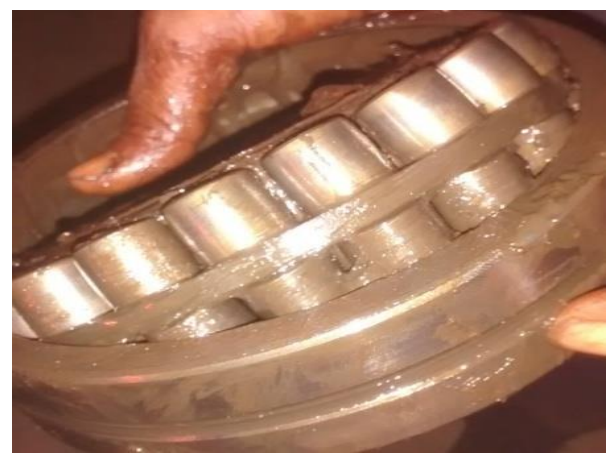

(a) Damaged pump DE bearing

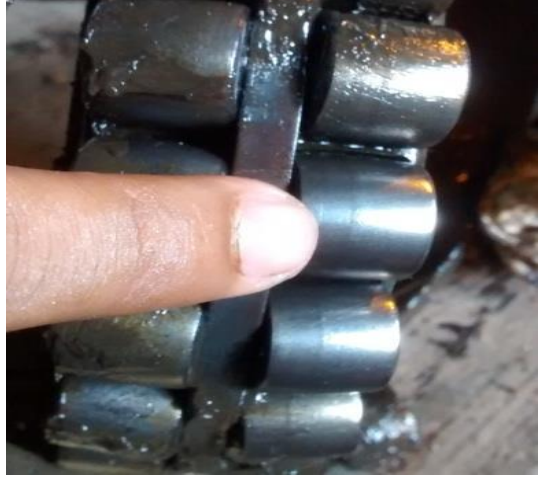

(b) Damaged pump DE bearing

Figure 8. Motor bearing in a damaged condition

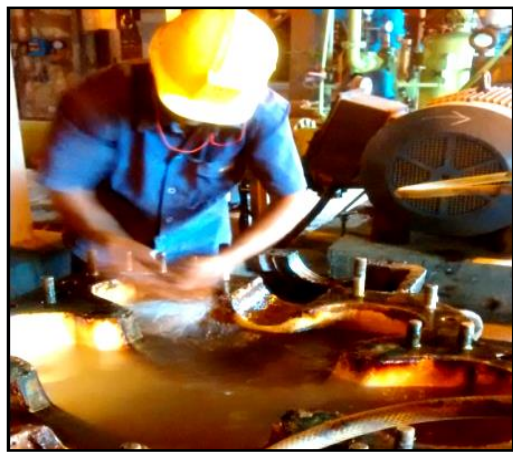

(a) Pump Internals and Pump impeller

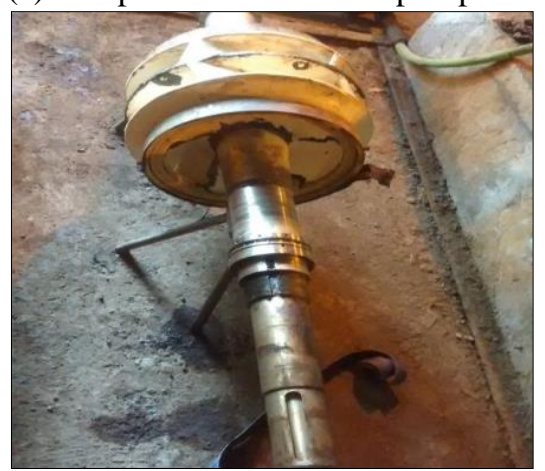

(b) Pump Internals and Pump impeller

Figure 9. Pump internals and pump impeller

Table 5. Vibration parameters of ACWP 1B

\begin{tabular}{cccc}
\hline $\begin{array}{c}\text { Vibration } \\
\text { Parameter }\end{array}$ & PUMP DE & PUMP NDE & Remark \\
\hline H $(\mathrm{mm} / \mathrm{sec})$ & 3.85 & 1.99 & $\begin{array}{c}\text { Within } \\
\text { limit } \\
\text { Within } \\
\text { V }(\mathrm{mm} / \mathrm{sec})\end{array}$ \\
limit \\
A (mm/sec) & 2.80 & 3.03 & $\begin{array}{c}\text { Within } \\
\text { limit } \\
\text { Within } \\
\text { limit }\end{array}$ \\
\hline
\end{tabular}

The maintenance work was carried out by replacing the pump bearing. The performance of ACWP 1B was analyzed after replacement of pump bearing. The vibration monitoring data was recorded using vibration analysis technique. The vibration spectrum after the maintenance is plotted in Figure 10 (a) to (h). The details of post-maintenance observations viz. velocity spectrum values and acceleration spectrum values obtained after maintenance using vibration analysis has been 


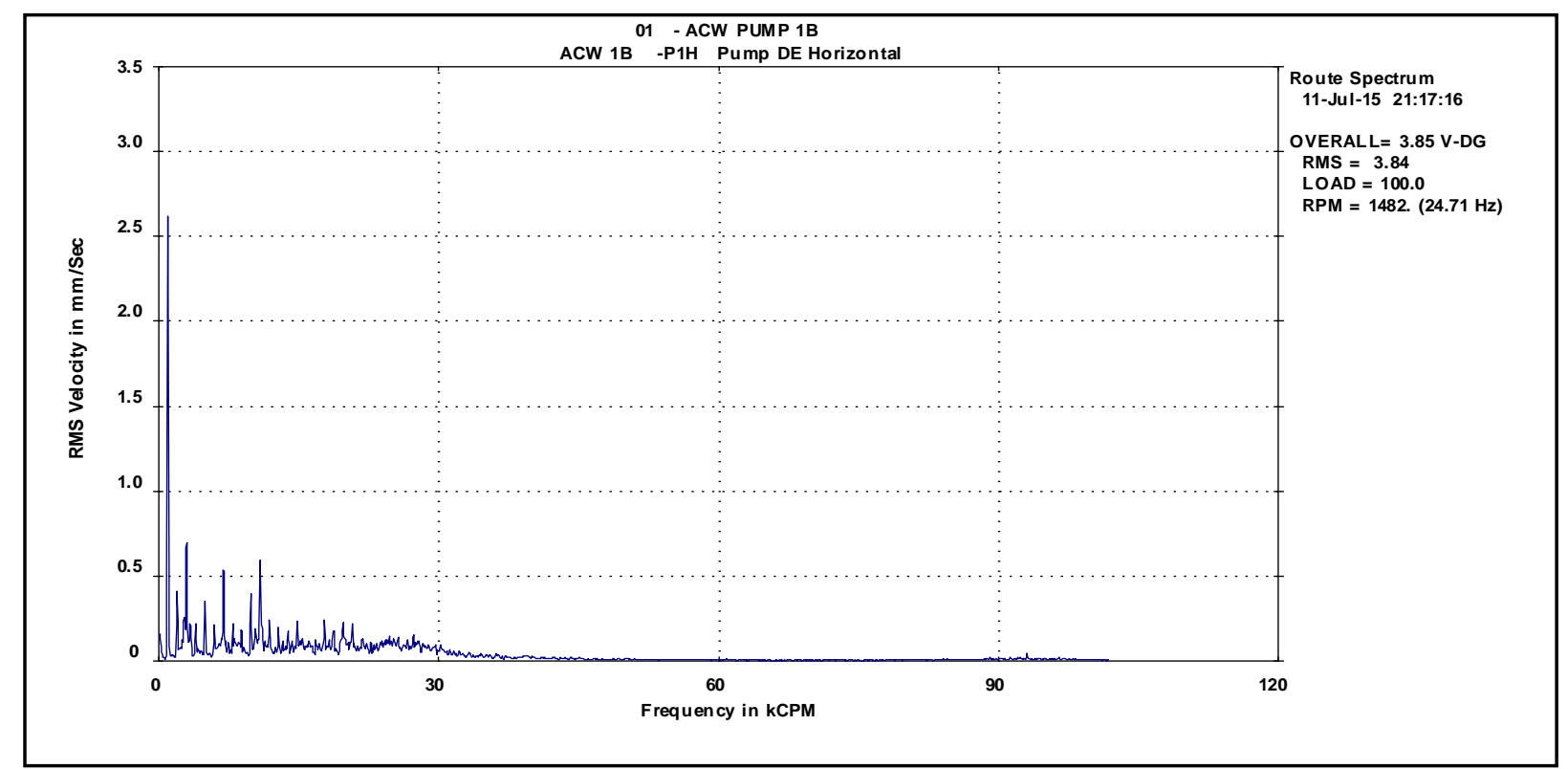

(a) Vibration spectrum (velocity) pump DE (horizontal)

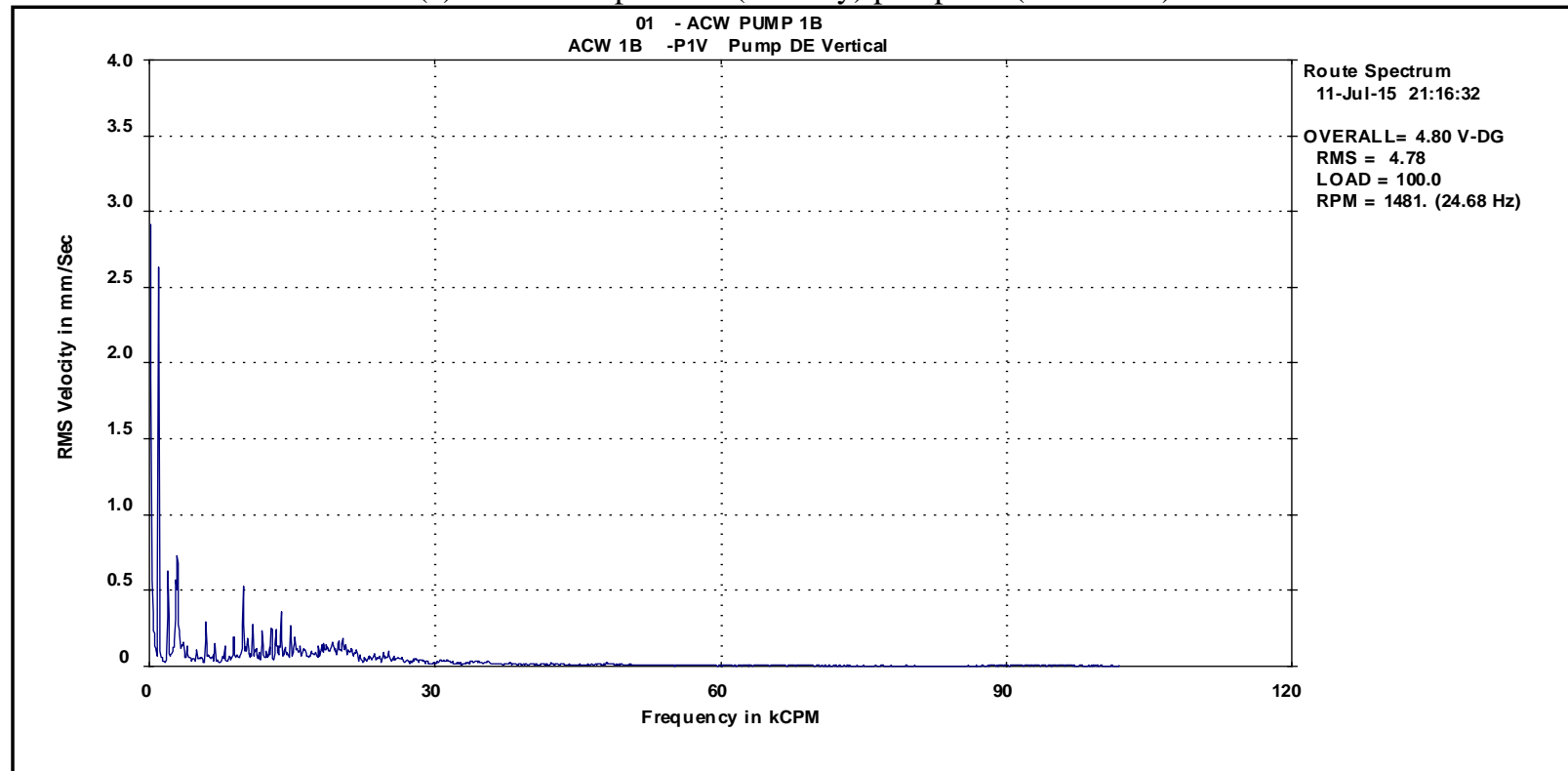

(b) Vibration spectrum (velocity) pump DE (vertical)

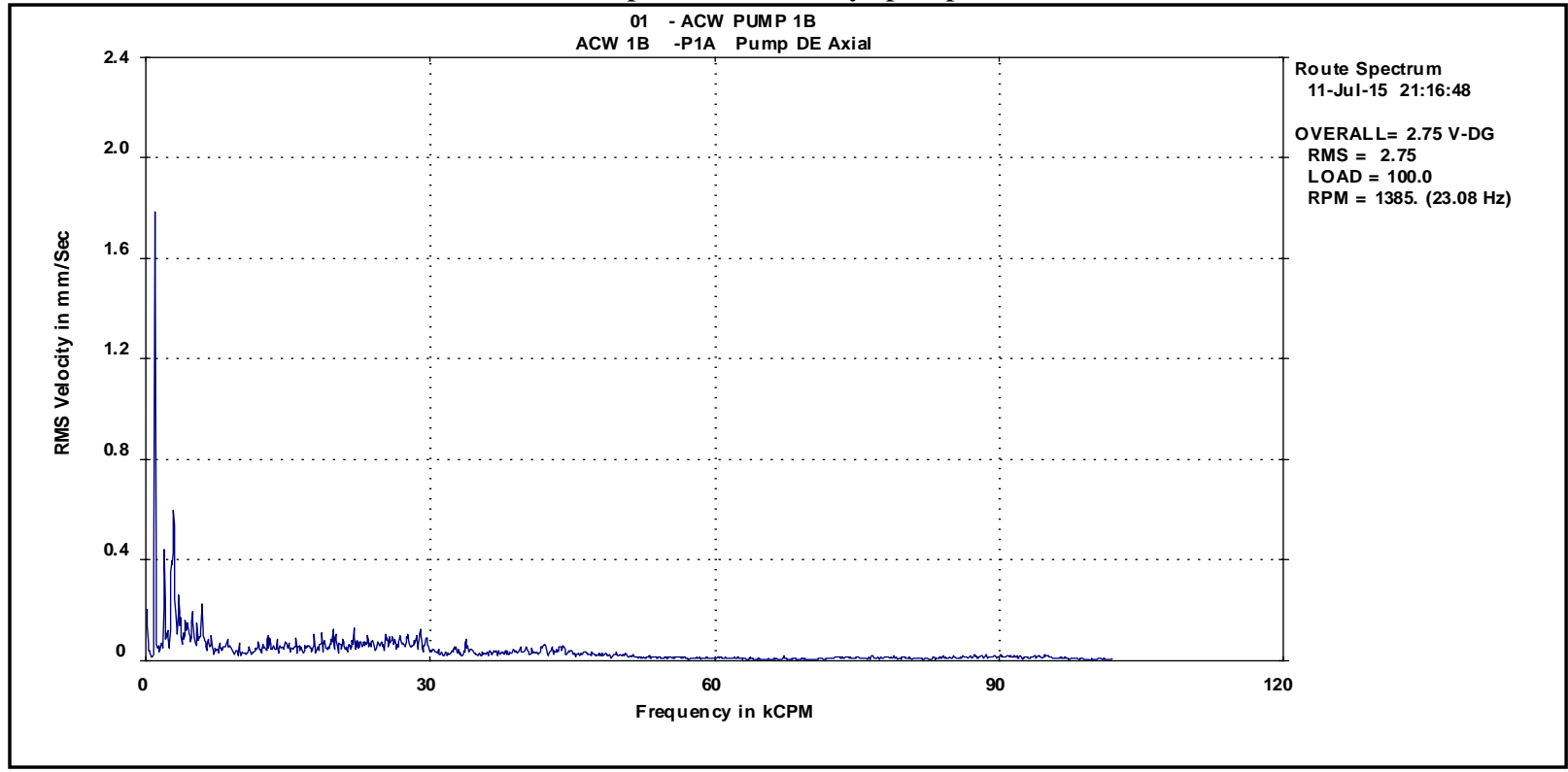

(c) Vibration spectrum (velocity) pump DE (axial) 


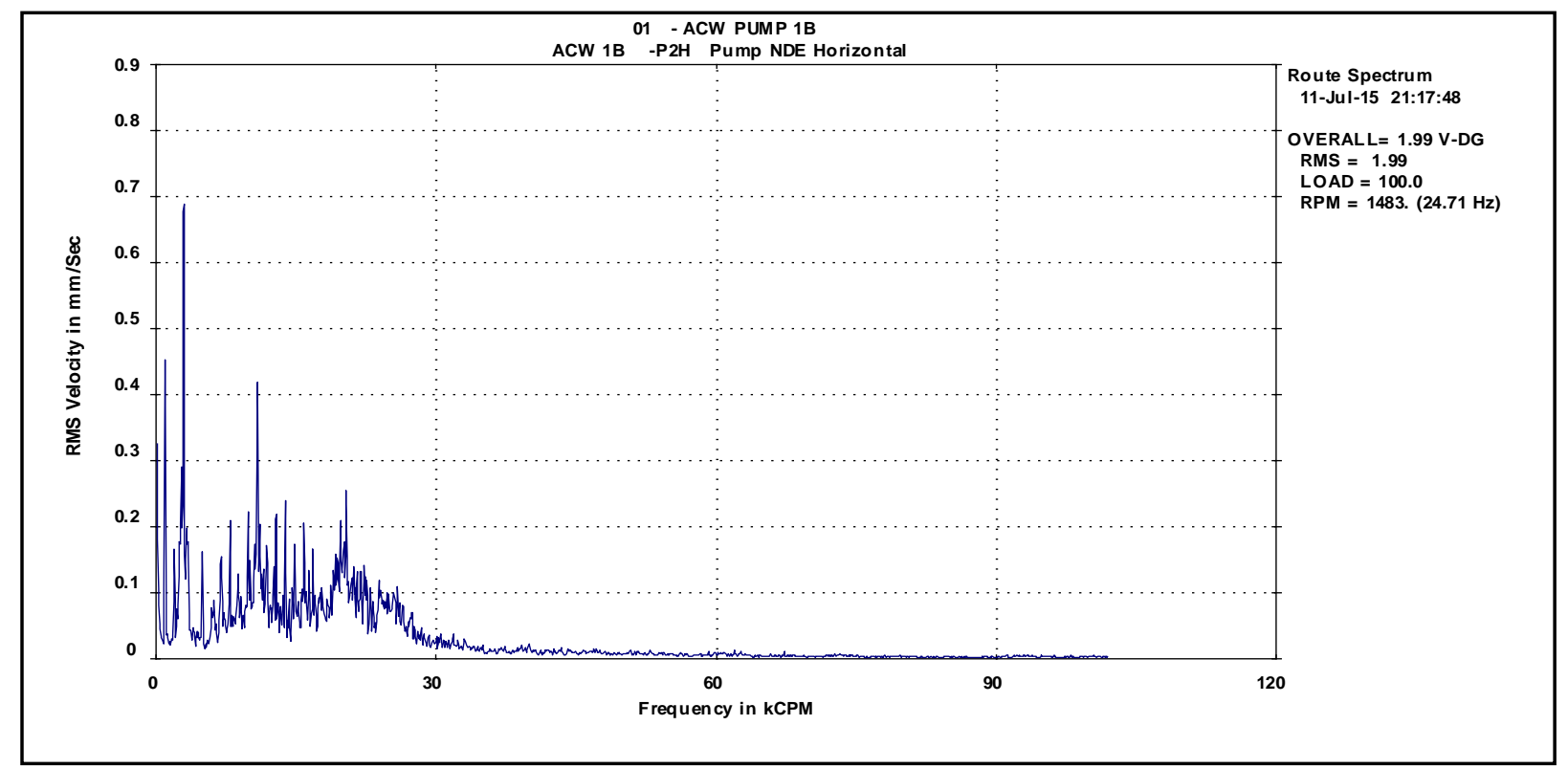

(d) Vibration spectrum (velocity) pump NDE (horizontal)

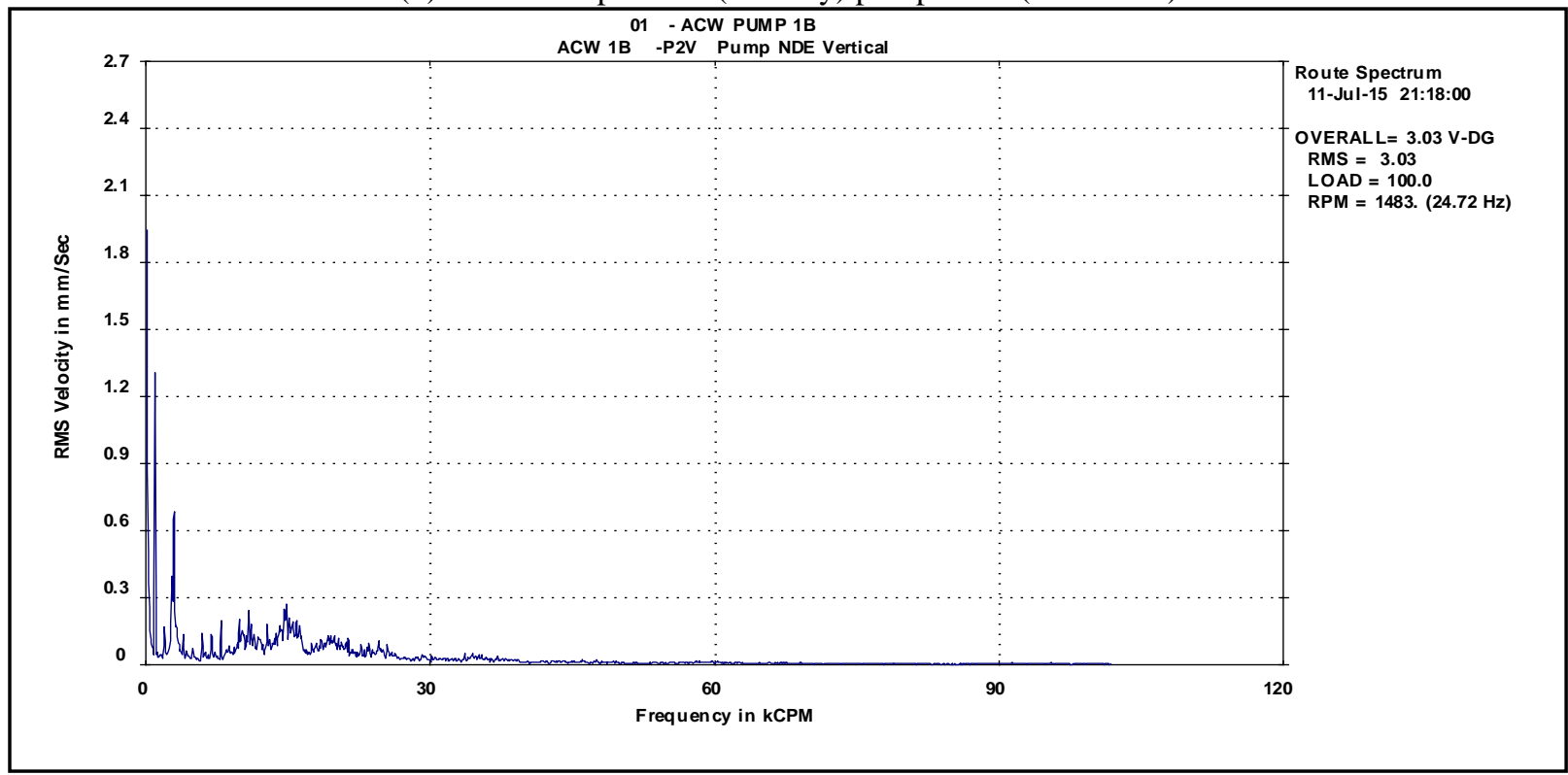

(e) Vibration spectrum (velocity) pump NDE (vertical)

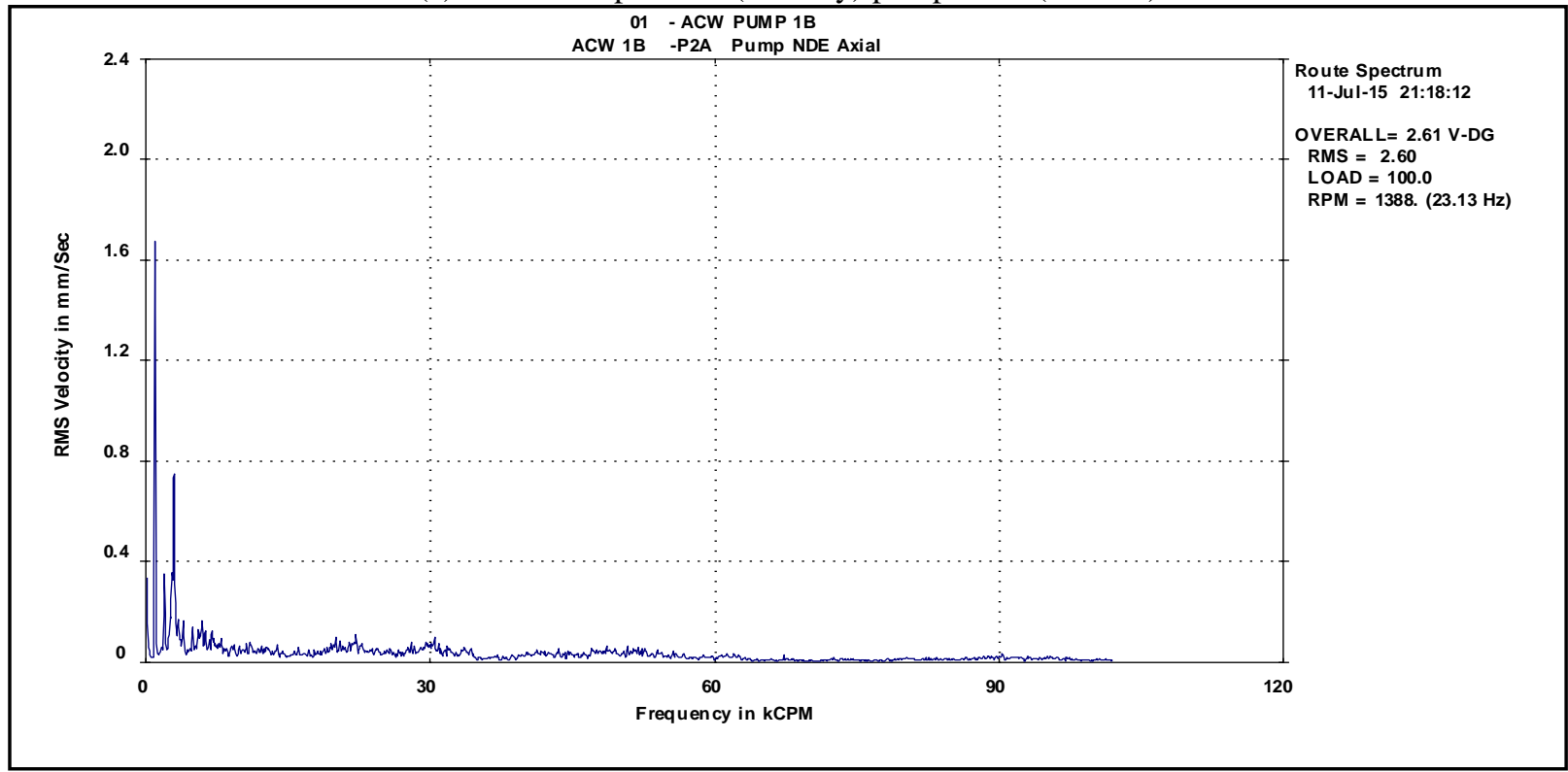

(f) Vibration spectrum (velocity) pump NDE (axial) 

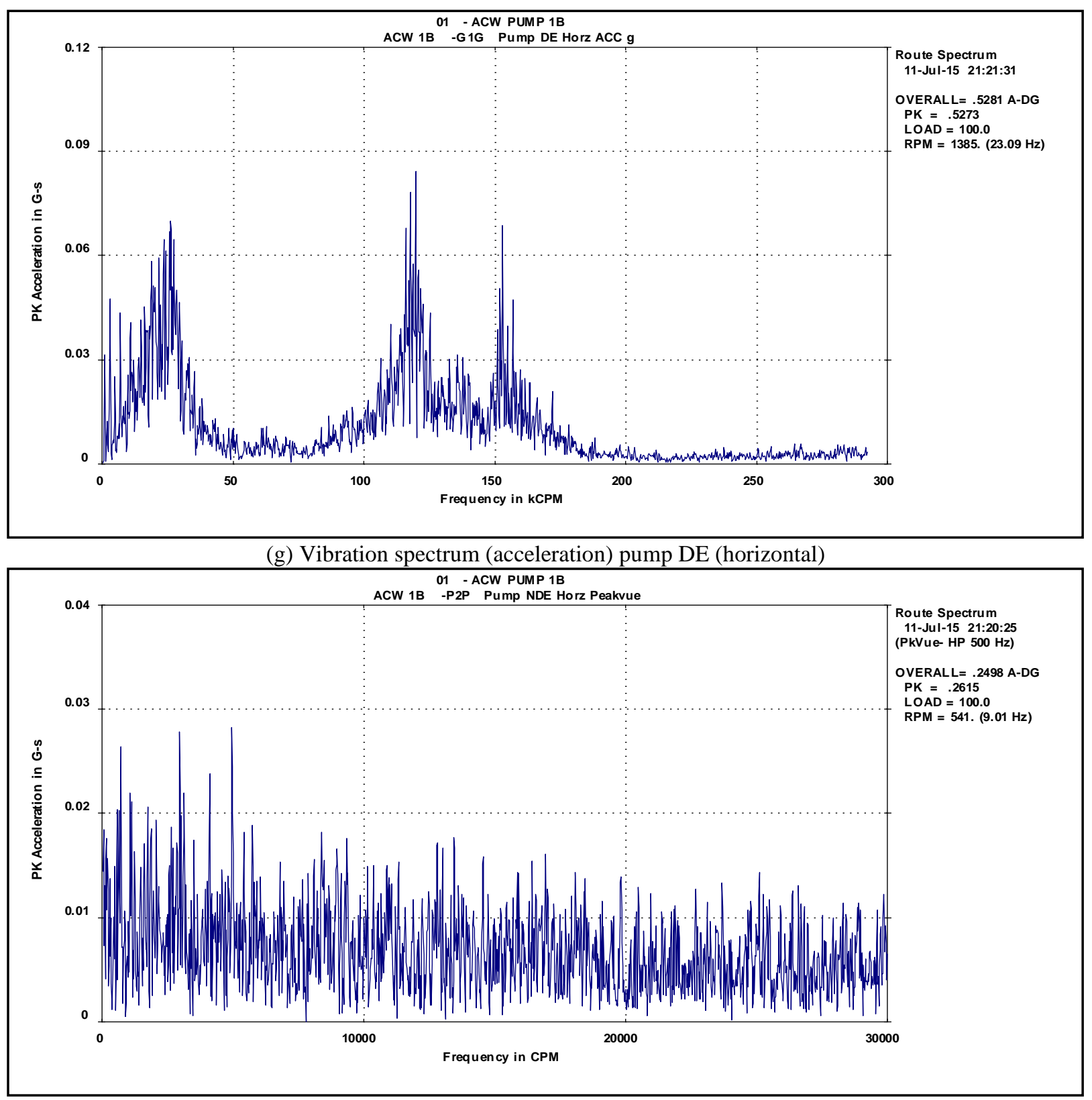

(h) Vibration spectrum (acceleration) pump NDE (horizontal)

Figure 10. Post maintenance vibration spectrum of ACWP-1B

\section{RESULTS AND DISCUSSIONS}

The reliability-based preventive maintenance interval for the condenser system of the thermal power plant is evaluated at various levels, such as at $90 \%, 75 \%$, and $50 \%$. It is observed that for CWP, the maintenance task should be completed before $4102 \mathrm{Hrs}$ for attaining the reliability level of $90 \%(\mathrm{R}=0.9)$. The CWP identified as the most critical equipment of the condenser system. Therefore, essential steps need to be taken to improve the reliability of such critical equipment of DTPP, which in turn enhance the system availability. In the case of other systems of the condenser system, it should complete before 11813 Hrs. With an intention to run equipment at $90 \%$ reliability level, it leads to high cost. So, the reliability of $75 \%$ level is advised for the beginning stages of operation and later on, the advantage of safety, effectiveness, and cost are accustomed to the superior level of reliability. Such determined reliability-based time interval is counted to plan not only maintaining/repairing work but also for replacement of the component/equipment.

The failure data and repair data of condenser system were analyzed for reliability analysis. The K-S Goodness test is carried out for determination of best-fit distribution curve for time to failure data and time to repair data of selected equipment. Most of the equipment of the condenser system follows a normal-2P distribution as best suited except CWP (Weibull-3P). The normal distribution shows a growing failure rate due to the aging of the component/equipment/system. It requires a consistently fixed interval of time to complete the maintenance task and repair actions. Hence, preventive maintenance is required for such component/equipment/system within a specified time interval. In the case of CWP, the shape parameter ' $\beta$ ' for Weibull distribution is less than 1 . It indicates that it is due to decreasing failure, which occurs in early life or debugging period for which the breakdown maintenance is best suitable. 
Furthermore, the overall system reliability of condenser system was evaluated at various time intervals. The result revealed that the overall system reliability of condenser system reduces rapidly after the operational time of $2160 \mathrm{Hrs}$. Moreover, reliability reduces to $61 \%$ for the operating time of $6480 \mathrm{Hrs}$. Hence, it is essential to note that CWP, CR, CT, and BRP affect the overall reliability of the condenser system. Therefore, necessary measures must be taken for such critical systems of a condenser system for improvement in reliability and availability of DTPP.

The coordinated condition monitoring approach was proposed for fault diagnosis. It was based on vibration analysis technique, noise measurement, and ultrasonic monitoring technique. The Auxiliary Cooling Water Pump 1B (ACWP) was identified as the most critical equipment. The condition monitoring data was collected for the ACWP $1 \mathrm{~B}$ equipment of thermal power plant using Vibration Analysis Technique. The vibration characteristics such as velocity and acceleration were compared with reference values. The trend of vibration signature analysis has been analyzed. The acceleration level found to be increased from $0.4 \mathrm{~g}$ to $1.6 \mathrm{~g}$ level. The sound level meter recorded the sound of $95 \mathrm{~dB}$ sound, and ultrasonic meter recorded the high-frequency sound of $15 \mathrm{~dB}$ close to the pump DE bearing. The coordinated condition monitoring approach has been implemented for diagnosing the fault of pump DE bearing of ACWP 1B. In the presence of a domain expert at the plant, the maintenance work has been carried out. During the maintenance work, it was found that pump bearings have been damaged. No Damage was observed on pump internals and pump impeller. The pump bearing was replaced, and the performance of ACWP 1B after maintenance work was analyzed. The vibration characteristics found to be within the normal range.

\section{CONCLUSION}

The reliability analysis of condenser system of Dahanu thermal power plant is determined and reported in this study. The preventive maintenance time interval is evaluated for planning the maintenance activity of the critical system of the plant. This study proposed a coordinated condition monitoring approach, including vibration analysis technique, noise monitoring, and ultrasound measurement for fault diagnosis of ACWP 1B of the condenser system. It was found that the pump driving end bearing was damaged. The important measures were taken and the pump bearing replaced with a new bearing. Through this study, the fault of pump motor bearing is avoided at an early stage of operation. Furthermore, an unplanned breakdown of the plant is also avoided. Improvement in reliability and availability has been achieved for the condenser system. This study strongly recommends to use coordinated condition monitoring approach with more than two / three condition monitoring techniques to improve timeliness and accuracy of fault diagnosis for other critical systems of the thermal power plant.

\section{ACKNOWLEDGMENT}

The author would like to thank Head of the Department, Suhas Patil, and Domain Experts Atul Deshpande and Hemant Bari of Dahanu Thermal Power Plant for their valuable guidance and comments. Also, the authors would like to acknowledge especially maintenance and planning department as a facilitator for data collection.

\section{REFERENCES}

[1] Garg, H. (2014). Reliability, availability and maintainability analysis of industrial systems using PSO and fuzzy methodology. MAPAN Journal of Metrology Society of India, 29(2): 115-129. https://doi.org/10.1007/s12647-013-0081-x

[2] Bhangu, N.S., Singh, R., Pahuja, G.L. (2018). Availability performance analysis of thermal power plants. J. Inst. Eng. Ser. C, 100(3): 439-448. https://doi.org/10.1007/s40032-018-0450-x

[3] Bhargava, C., Banga, V.K., Singh, Y. (2016). Improved reliability, accuracy and failure minimization of spacecraft satellite architecture by using fuzzy logic. Int. J. Control Theory and Applications, 9(41): 523-532.

[4] Eti, M.C., Ogaji, S.O.T., Probert, S.D. (2007). Integrating reliability, availability, maintainability and supportability with risk analysis for improved operation of the Afam thermal power-station. Appl. Energy, 84: 202-221. https://doi.org/10.1016/j.apenergy.2006.05.001

[5] Kumar, R., Sharma, A.K., Tewari, P.C. (2012). Markov approach to evaluate the availability simulation model for power generation system in a thermal power plant. International Journal of Industrial Engineering Computations, 3: 743-750. https://doi.org/10.5267/j.ijiec.2012.08.003

[6] Dev, N., Samsher, Kachhwaha, S.S., Attri, R. (2014). Development of reliability index for combined cycle power plant using graph theoretic approach. Ain Shams Eng. J., 5: 193-203. https://doi.org/10.1016/j.asej.2013.09.010

[7] Carazas, F.J.G., Salazar, C.H., Souza, G.F.M. (2011). Availability analysis of heat recovery steam generators used in thermal power plants. Energy, 36: 3855-3870. https://doi.org/10.1016/j.energy.2010.10.003

[8] Garg, H., Rani, M., Sharma, S.P. (2013). An efficient two phase approach for solving reliability-redundancy allocation problem using artificial bee colony technique. Computers \& Operations Research, 40(12): 2961-2969. http://dx.doi.org/10.1016/j.cor.2013.07.014

[9] Garg, H. (2015). An approach for solving constrained reliability-redundancy allocation problems using cuckoo search algorithm. Beni-Suef University Journal of Basic and Applied Sciences, 4(1): 14-25. http://dx.doi.org/10.1016/j.bjbas.2015.02.003

[10] Kumar, R., Sharma, K., Tewari, P.C. (2013). Performance evaluation of a coal-fired power plant. Int. J. Performability Eng., 9(10): 455-461.

[11] Barabady, J., Kumar, U. (2008). Reliability analysis of mining equipment: A case study of a crushing plant at Jajarm Bauxite Mine in Iran. Reliab. Eng. Syst. Saf., 93: 647-653. https://doi.org/10.1016/j.ress.2007.10.006

[12] Bhargava, C., Banga, V.K., Singh, Y. (2016). Reliability prediction of thyristor using artificial intelligence techniques. Indian Journal of Science and Technology, 9(18):

1-6. https://doi.org/10.17485/ijst/2016/v9i18/88564

[13] Deng, L., Zhao, R. (2013). A vibration analysis method based on hybrid techniques and its application to rotating 
machinery. Measurement, 46: 3671-3682. https://doi.org/10.1016/j.measurement.2013.07.014

[14] Peng, Z., Kessissoglou, N. (2003): An integrated approach to fault diagnosis of machinery using wear debris and vibration analysis. Wear, 255: 1221-1232. https://doi.org/10.1016/S0043-1648(03)00098-X

[15] Jagtap, H.P., Bewoor, A. (2017). Development of an algorithm for identification and confirmation of fault in thermal power plant equipment using condition monitoring technique. Proceedia Engineering, 181: 690697. https://doi.org/10.1016/j.proeng.2017.02.451

\section{NOMENCLATURE}

R

DE

NDE

$\mathrm{dB}$

g
DTPP
Reliability

diving end

non-driving end

decibel

gravitational acceleration, $\mathrm{m} . \mathrm{s}^{-2}$

dahanu thermal power plant
$\mathrm{K}-\mathrm{S}$

CWP

CR

CT

BCR

$\mathrm{H}$

V

A

\section{Greek symbols}

$\beta$

$\theta$

$\mathrm{t}$

$\gamma$

$\sigma$

\section{Subscripts}

S

system

$\beta$
$\theta$
$\gamma$
$\sigma$
Subscripts

time cooling water pump

condenser

condenser tube

ball recirculating pump

horizontal vibration parameter, $\mathrm{mm} / \mathrm{sec}$

vibration parameter, $\mathrm{mm} / \mathrm{sec}$

vibration parameter, $\mathrm{mm} / \mathrm{sec}$
Kolmogorov-Smirnov

shape parameter scale parameter

location parameter

variance 